\title{
Use of Coarse-Resolution Models of Species' Distributions to Guide Local Conservation Inferences
}

\author{
A. MÁRCIA BARBOSA,${ }^{*} †$ RAIMUNDO REAL,$\ddagger$ AND J. MARIO VARGAS $\ddagger$ \\ ${ }^{*}$ CIBIO, University of Évora, Largo dos Colegiais, 7004-516 Évora, Portugal, email barbosa@uevora.pt \\ †Department of Biological Sciences, Imperial College London, Silwood Park Campus, Ascot, Berkshire SL5 7PY, United Kingdom \\ $\ddagger$ Biogeography, Diversity and Conservation Lab, Department of Animal Biology, Faculty of Sciences, University of Málaga, Málaga \\ 29071, Spain
}

\begin{abstract}
Distribution models are used increasingly for species conservation assessments over extensive areas, but the spatial resolution of the modeled data and, consequently, of the predictions generated directly from these models are usually too coarse for local conservation applications. Comprehensive distribution data at finer spatial resolution, however, require a level of sampling that is impractical for most species and regions. Models can be downscaled to predict distribution at finer resolutions, but this increases uncertainty because the predictive ability of models is not necessarily consistent beyond their original scale. We analyzed the performance of downscaled, previously published models of environmental favorability (a generalized linear modeling technique) for a restricted endemic insectivore, the Iberian desman (Galemys pyrenaicus), and a more widespread carnivore, the Eurasian otter (Lutra lutra), in the Iberian Peninsula. The models, built from presence-absence data at $10 \times 10 \mathrm{~km}$ resolution, were extrapolated to a resolution 100 times finer $(1 \times$ $1 \mathrm{~km}$ ). We compared downscaled predictions of environmental quality for the two species with published data on local observations and on important conservation sites proposed by experts. Predictions were significantly related to observed presence or absence of species and to expert selection of sampling sites and important conservation sites. Our results suggest the potential usefulness of downscaled projections of environmental quality as a proxy for expensive and time-consuming field studies when the field studies are not feasible. This method may be valid for other similar species if coarse-resolution distribution data are available to define high-quality areas at a scale that is practical for the application of concrete conservation measures.
\end{abstract}

Keywords: distribution modeling, downscaling, environmental favorability, environmental quality, Eurasian otter, Galemys pyrenaicus, Iberian desman, Iberian Peninsula, Lutra lutra, model extrapolation

Uso de Modelos de Resolución Gruesa de las Distribuciones de Especies para Guiar Inferencias de Conservación Locales

Resumen: Los modelos de distribución son cada vez más usados para evaluaciones de conservación en áreas extensas, pero la resolución espacial de los datos modelados y, consecuentemente, las predicciones generadas directamente por estos modelos generalmente es muy gruesa para acciones locales de conservación. Sin embargo, la obtención de datos de distribución a una resolución más fina requiere un nivel de muestreo que es impráctico para la mayoría de las especies y regiones. La escala de los modelos puede ser reducida para predecir la distribución en resoluciones más finas, pero esto incrementa la incertidumbre porque la babilidad predictiva de los modelos no necesariamente es consistente más allá de su escala original. Analizamos el funcionamiento de modelos previamente publicados de favorabilidad ambiental (una técnica para modelos lineales generalizados) con reducciones de escala, en un insectívoro endémico restringido, Galemys pyrenaicus, y un carnívoro más ampliamente distribuido, la nutria euroasiática (Lutra lutra), en la Península Ibérica. Los modelos, construidos con datos de presencia-ausencia con una resolución de $10 \times 10 \mathrm{~km}$, fueron extrapolados a una resolución 100 veces más fina $(1 \times 1 \mathrm{~km})$. Comparamos las predicciones reescaladas de calidad 
ambiental para las 2 especies con datos publicados de observaciones locales y de sitios importantes para la conservación propuestas por expertos. Las predicciones estuvieron significativamente relacionadas con la presencia o ausencia de las especies y con los sitios de muestreo y de importancia para la conservación seleccionadas por los expertos. Nuestros resultados sugieren la utilidad potencial de las proyecciones con reducción de escala de la calidad ambiental como una alternativa a estudios de campo costosos y dispendiosos cuando los estudios de campo no son factibles. Este método puede ser válido para otras especies similares si hay disponibilidad de datos de distribución de grano grueso para definir áreas de calidad alta a una escala que es práctica para la aplicación de medidas de conservación concretas.

Palabras Clave: calidad ambiental, extrapolación de modelo, favorabilidad ambiental, Galemys pyrenaicus, Lutra lutra, modelos de distribución, nutria euroasiática, Península Ibérica, reducción de escala

\section{Introduction}

Models of species distributions ideally can predict the most likely areas for species presence from a sample of distribution data and their correlated environmental variables (Guisan \& Zimmermann 2000). The use of models is increasingly required in conservation assessments conducted over extensive areas. Nevertheless, on the one hand, the resolution at which distribution data for large regions are available is usually too coarse to be applied to local conservation planning, and on the other hand, the collection of distribution data at a finer resolution requires high levels of sampling effort, which is possible for only a few species and over small areas.

Models can be downscaled to predict local distributions from coarse-resolution data. Barbosa et al. (2003) downscaled a distribution model of Eurasian otters (Lutra lutra) in the Iberian Peninsula from $10 \times 10$ to $1 \times 1 \mathrm{~km}$ squares, but they did not assess quantitatively the fit of downscaled predictions with local observations. Araújo et al. (2005) successfully downscaled distribution models of British birds from $50 \times 50$ to $10 \times 10 \mathrm{~km}$ squares, but their downscaled models were still too coarse for application to local conservation efforts.

The extrapolation of models built at one resolution to different resolutions increases the uncertainty of model predictions, because techniques of model evaluation apply only to the model's original scale and errors can vary among scales (Araújo et al. 2005). We examined the possibility of applying coarse-resolution $(10 \times 10 \mathrm{~km})$ distribution models to local conservation planning by extrapolating predictions to a resolution 100 times finer than the modeled data. We assessed the downscaled performance of published distribution models of two species for which local distribution data were available for validation: the Iberian desman (Galemys pyrenaicus) and the Eurasian otter. These species belong to different trophic guilds and have different biogeographic traits.

The Iberian desman (Soricomorpha: Talpidae) is a micromammalian insectivore that mainly inhabits cold mountain waters. It is endemic to the Pyrenees and the northern Iberian Peninsula. Models of desman distribution at $10 \times 10 \mathrm{~km}$ resolution were built by Barbosa et al. (2009). In Portugal a national survey recorded local presence data, and on the basis of detailed field knowledge sites important for desman conservation have been identified (Queiroz et al. 1998). In Spain published data on local presences and absences of desman exist for the regions of Catalonia and La Rioja (Aymerich et al. 2001; Aguirre-Mendi 2004).

The Eurasian otter (Carnivora: Mustelidae) is a mesomammalian predator that occupies a variety of permanent and temporary aquatic environments, from the highlands to the coast (Ruiz-Olmo \& Delibes 1998; Palomo \& Gisbert 2002). Its geographic range includes most of the Iberian Peninsula and, in terms of spatial extent and environmental conditions, is one of the widest among Palaearctic mammals (Ruiz-Olmo et al. 2008). Otter distribution in Spain at $10 \times 10 \mathrm{~km}$ resolution was modeled by Barbosa et al. (2003). Local presence and absence data are also available for the Spanish mainland (Ruiz-Olmo \& Delibes 1998).

We compared downscaled predictions of these previously published $10 \times 10 \mathrm{~km}$ models with local distribution data and with experts' recommendations on important sites for conservation of these two species. Our aim was to assess whether coarse-resolution distribution models can provide a sound basis for local conservation efforts where empirical data are missing and difficult to obtain.

\section{Methods}

\section{Study Area and Data}

The Iberian Peninsula in southwestern Europe (Fig. 1) is part of the Mediterranean Basin, which has one of the world's highest regional concentrations of species richness (Mittermeier et al. 2004). The peninsula is mainly composed of the mainland territories of Portugal (approximately $15 \%$ ) and Spain (approximately $85 \%$ ), and is nearly $600,000 \mathrm{~km}^{2}$. The Pyrenean Mountains cross the contact zone between the peninsula and the rest of Europe, limiting biotic and abiotic interactions and making Iberia a discrete biogeographic unit.

Barbosa et al. (2003) used logistic regression to model otter distribution in Spain with presence and absence 


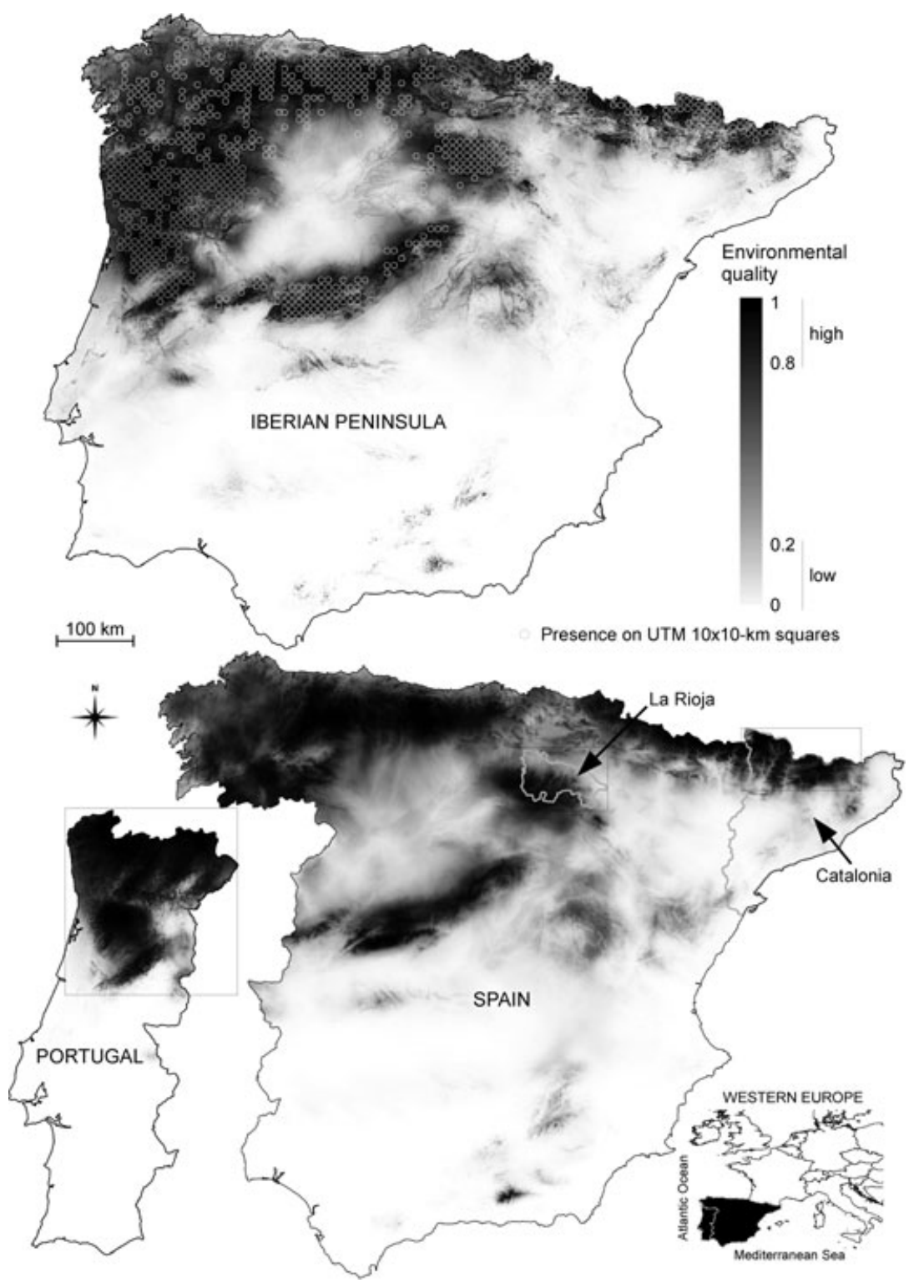

Figure 1. Environmental quality for Iberian desmans in the Iberian Peninsula (top), Portugal (bottom left), and Spain (bottom right) as modeled by Barbosa et al. (2009) from presence-absence data at the resolution of $10 \times 10 \mathrm{~km}$ (top; after Queiroz et al. 1998 and Palomo \& Gisbert 2002) and downscaled here to $1 \times 1 \mathrm{~km}$. data from a national otter survey displayed on a $10 \times$ $10 \mathrm{~km}$ grid and then downscaled predictions to $1 \times 1 \mathrm{~km}$ resolution. Barbosa et al. (2009) used another generalized linear model, which Real et al. (2006) called the favorability function, to model desman distribution at $10 \times 10 \mathrm{~km}$ resolution in Portugal only, in Spain only, and in the entire Iberian Peninsula. The favorability function is based on logistic regression but uses a modification to the logit link to eliminate the effect of species prevalence on the predicted values

$$
F=e^{y} /\left(n_{1} / n_{0}+e^{y}\right),
$$

where $F$ is the logit link of the favorability function, $e$ is the Neperian number, $y$ is the logistic regression model equation, and $n_{1}$ and $n_{0}$ are the numbers of presences and absences, respectively (Real et al. 2006). The favorability function has been used in a number of modeling studies (e.g., Vargas et al. 2007; López-Darias et al. 2008;
Real et al. 2009; Gutiérrez Illán et al. 2010). To allow direct comparability among all models in this study, we converted the probability of otter presence (given by logistic regression; Barbosa et al. 2003) into favorability (or environmental quality) for otters (with Eq. 7 of Real et al. 2006). Following the procedure described for the otter (Barbosa et al. 2003), we downscaled the desman models by using a map calculator to apply the model equations to the variable maps at a resolution of 1 pixel $\approx 1 \mathrm{~km}^{2}$. These variables included several spatial, environmental, topographic, and anthropogenic factors (Table 1).

We then gathered data on local distribution for both these species so we could compare these data with downscaled model predictions. For the otter, data were available for each of the 47 mainland Spanish provinces (1335 presence and 2576 [surveyed] absence points; Ruiz-Olmo \& Delibes 1998). For the desman, fine-resolution data were available for three Iberian areas: the Spanish regions 
Table 1. Variables included in the analyzed models and their relation (either positive $[+]$ or negative $[-]$ ) with the species in each model (Barbosa et al. 2003; Real et al. 2009).

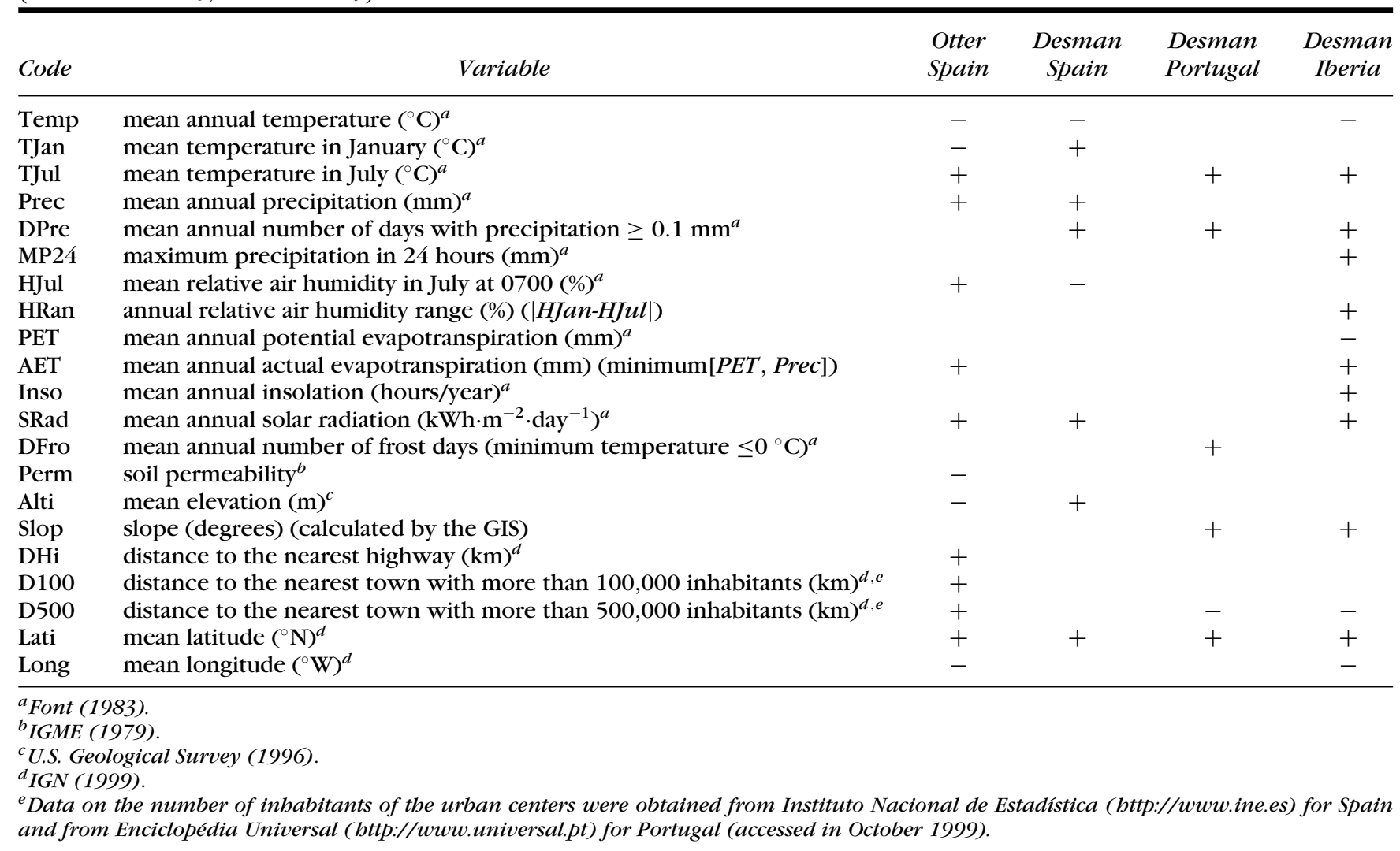

of Catalonia (111 presences, 295 absences; Aymerich et al. 2001), La Rioja (90 presences, 42 absences; AguirreMendi 2004), and the northern half of Portugal (207 presences, no reported absences; Queiroz et al. 1998) (Fig. 2). We also recorded a set of river stretches important for desman conservation, which Queiroz et al. (1998) defined in Portugal on the basis of field observations and expert knowledge (Fig. 2).

We used Quantum GIS 1.2.0 (Quantum GIS Development Team 2009) to georeference all local maps to the Universal Transverse Mercator coordinate system (zone 30N, European Datum 1950) and to digitize their data on species distribution and important conservation areas. We then imported the data into GRASS (Geographic Resources Analysis Support System; GRASS Development Team 2009) with Quantum GIS's GRASS plugin and overlaid them to our downscaled model predictions. Statistical analyses were carried out in R 2.8.1 (R Development Core Team 2009).

\section{Downscaled Predictions and Species Occurrence}

We used the GRASS v.what.rast module to extract the environmental quality values predicted by the downscaled models for each location with observed distribution data. We then used R's wilcox.test function to perform Mann-Whitney-Wilcoxon rank-sum tests (here- after called Wilcoxon tests) to check whether presence points had higher environmental quality values than absence points.

We also assessed the capacity of the downscaled models to discriminate between observed presence and absence points by analyzing their receiver operating characteristic (ROC) curves in the ROCR R package (Sing et al. 2005). The area under this curve (AUC) provides a single-number discrimination measure across all possible classification thresholds for each model and thus avoids the subjectivity of threshold selection (Fielding \& Bell 1997).

\section{Proportion of Presences in Areas of Predicted High and Low Quality}

The predictions generated by the models are continuous values. To predict the distribution of a species, it is necessary to define a limit of environmental quality above which to consider that the model predicts an area as suitable for the presence of a species. Areas with similar prediction outputs, however, should not be considered as markedly different from each other only because they are located on different sides of an arbitrary suitability threshold (Hosmer \& Lemeshow 2000). Consequently, a range of environmental quality values should be set between those considered suitable and unsuitable. Rojas 

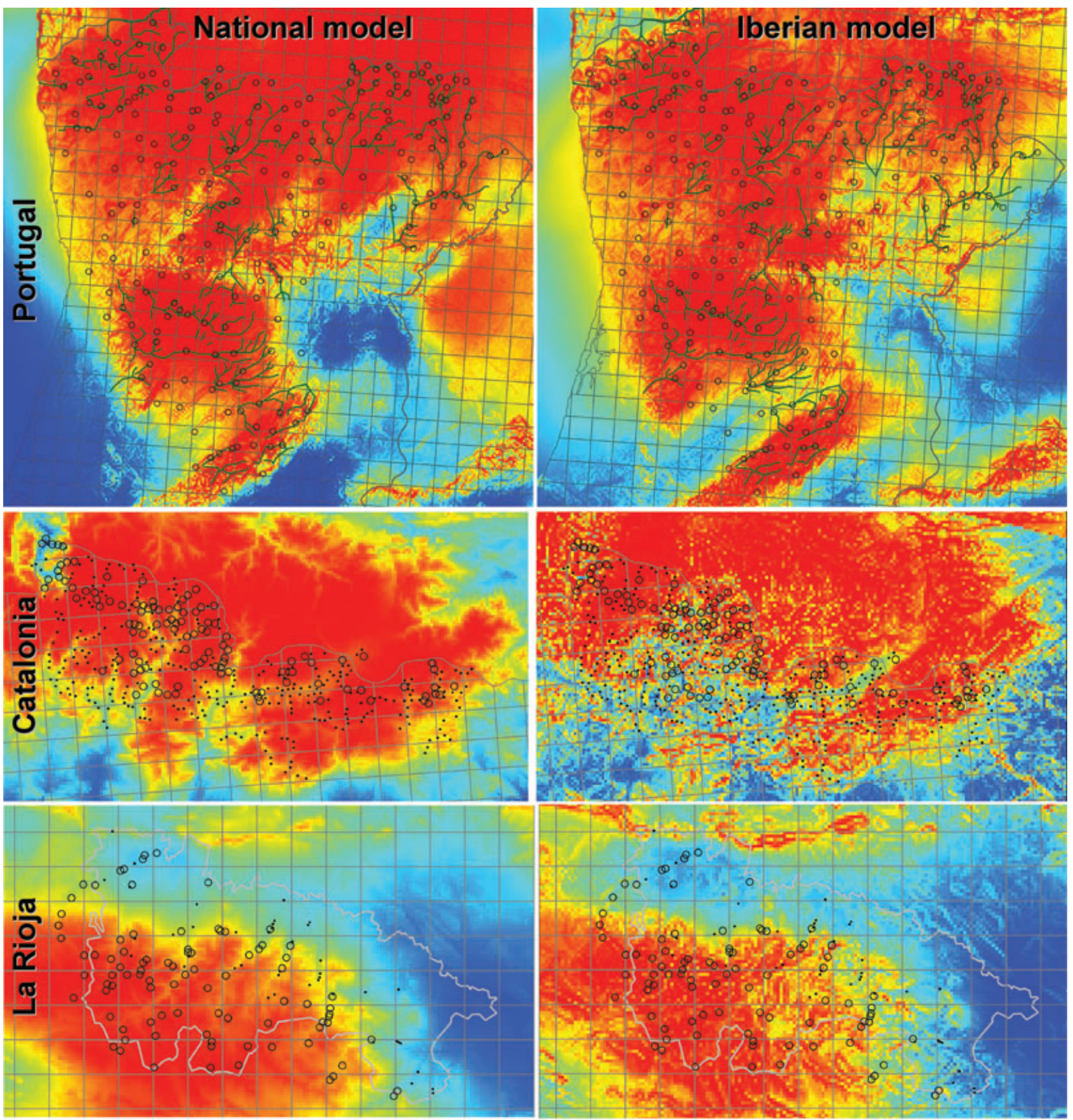

- Presence

- Absence

- Important conservation sites
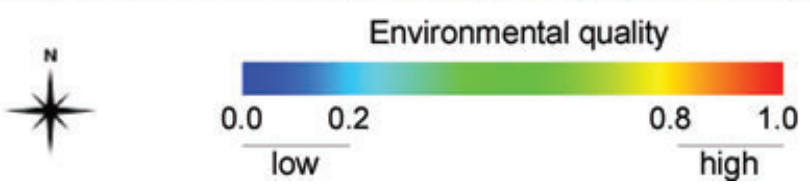

Figure 2. Environmental quality for Iberian desmans according to the national (Portuguese for Portugal and Spanish for Catalonia and La Rioja) and Iberian models of distribution compared with actual fine-resolution presence and absence data (Queiroz et al. 1998; Aymerich et al. 2001; Aguirre-Mendi 2004) and with important conservation sites for this species in Portugal (Queiroz et al. 1998). Environmental quality values are at the $1 \times 1$ $\mathrm{km}$ resolution and were derived from $10 \times 10 \mathrm{~km}$ modeled data. The limits of countries or regions and the $10 \times$ $10 \mathrm{~km}$ squares are displayed for reference. 
et al. (2001) suggest defining the suitability threshold at the output value where the predicted odds in favor of the species' presence are greater than 4:1 and the unsuitability threshold where those odds are less than 1:4 (see also Muñoz et al. 2005). Thus, we set this range between the quality values of 0.2 and 0.8 .

We then assessed, for both the 10 and $1-\mathrm{km}^{2}$ resolution models, whether the number of presences in high-quality $(F \geq 0.8)$ and low-quality $(F \leq 0.2)$ areas were different from those expected by chance. Thus, we compared the proportion of presences within each of these areas with the proportion of localities $(10 \times 10 \mathrm{~km}$ grid cells or $1 \times 1 \mathrm{~km}$ pixels) available within those areas with the $\mathrm{R}$ prop.test function. We obtained the number of map pixels in each category from GRASS with the r.recode program (obtaining, for each category, a map in which pixels within that category had a value of 1 and all other pixels had a value of 0 ) followed by r.sum, which summed the pixel values of each category in each map.

\section{Downscaled Predictions and Selection of Survey Sites}

We checked whether surveyed sites (presences and absences together) had higher predicted environmental quality than randomly selected sites because selection of sampling sites is related to the surveyors' perceptions of environmental suitability for the species they are searching for. We used the r.random module in GRASS to generate 1000 random site samples for each region we analyzed (mainland Spain for the otter; northern Catalonia, La Rioja, and northern Portugal for the desman [Fig. 1]). Each sample of randomly selected sites had the same number of points as the distribution data sample available in its region. The random points were generated within the limits of each country's territory and the limits of a rectangular window that encompassed the sites surveyed in each region (Fig. 1). We then used Wilcoxon tests to compare downscaled environmental quality at surveyed sites and at randomly selected sites in each region.

\section{Downscaled Predictions and Important Conservation Areas}

We used v.to.rast in GRASS to define the $1 \times 1 \mathrm{~km}$ pixels crossed by the river stretches (Queiroz et al. 1998) considered important for conservation of the Iberian desman (Fig. 2). We then generated points at the center of these pixels (with r.to.vect) and used v.what.rast to obtain their predicted quality values. We used Wilcoxon tests in $\mathrm{R}$ to determine whether predicted quality was higher at important conservation sites than in the remaining territory.

\section{Results}

The four models we analyzed showed good predictive capacity at their original $10 \times 10 \mathrm{~km}$ resolution. The
AUC was 0.795 for the otter model and 0.944, 0.972, and 0.938 for the Iberian, Portuguese, and Spanish models of desman distribution, respectively (Barbosa et al. 2003, 2009).

When downscaled to a resolution of $1 \times 1 \mathrm{~km}$, the models revealed local gradients of distribution that were not detectable with the modeled data, which had a coarse resolution (Figs. 1-3). Predicted environmental quality values varied considerably within the $10 \times 10 \mathrm{~km}$ squares because high-favorability and low-favorability areas were distinguished clearly at the finer resolution $(1 \times 1 \mathrm{~km})$. For desmans, areas that had relatively homogeneous quality in the national models for Portugal and Spain had more heterogeneous quality in the Iberian model (Figs. $1 \& 2$ ).

Downscaled environmental quality values generally matched the fine-resolution distribution data (Figs. $2 \&$ 3). The downscaled model for otters showed good performance throughout Spain $(\mathrm{AUC}=0.765)$. The downscaled models for desmans performed better in La Rioja (AUC = 0.823 for the Spanish model and 0.809 for the Iberian model) than in Catalonia (AUC $=0.570$ for the Spanish model and 0.603 for the Iberian model). Mean environmental quality was always significantly higher at presence sites than at absence sites for both otter (Wilcoxon test, $p<0.001$ ) and desman (La Rioja: $p<0.001$ for both Iberian and Spanish models; Catalonia: $p<0.01$ for the Iberian model and $p<0.05$ for the Spanish model).

The proportion of observed presences in areas of predicted high quality $(\geq 0.8)$ was always significantly higher than expected by chance (i.e., than the proportion of localities available within those areas) for both the original and the downscaled models (Wilcoxon tests, $p<0.001$ ). The proportion of presences in areas of low quality $(\leq 0.2)$ was generally lower than expected by chance. The differences were highly significant for all original 10$\mathrm{km}^{2}$ models and for the downscaled $(1 \times 1 \mathrm{~km})$ models of otters and Portuguese desmans $(p<0.001)$. Significance values for the downscaled Iberian model of desmans were $p=0.02$ in Portugal, $p=0.06$ in La Rioja and $p=0.08$ in Catalonia. For the downscaled model of Spanish desmans, differences between the proportion of localities with low predicted quality and the proportion of presences within those localities were not significant, which may have been due to the low sample size in this category in La Rioja ( $0 \%$ presences in 3\% low-quality area) and Catalonia ( $0.5 \%$ presences in $1 \%$ low-quality area).

Mean environmental quality values were consistently higher at surveyed sites than at each of the 1000 random site samples for all models and regions, with the exception of two samples in La Rioja for the Spanish model of desmans. This difference was significant (Wilcoxon tests, $p<0.05$ ) in $100 \%$ of the random samples for the model of otters; in $100 \%$ of the Portuguese random samples for models of both Iberian and Portuguese desmans (but only presences were analyzed here); in $67.6 \%$ and $99.6 \%$ of the Catalonian random samples for the Spanish and Iberian 


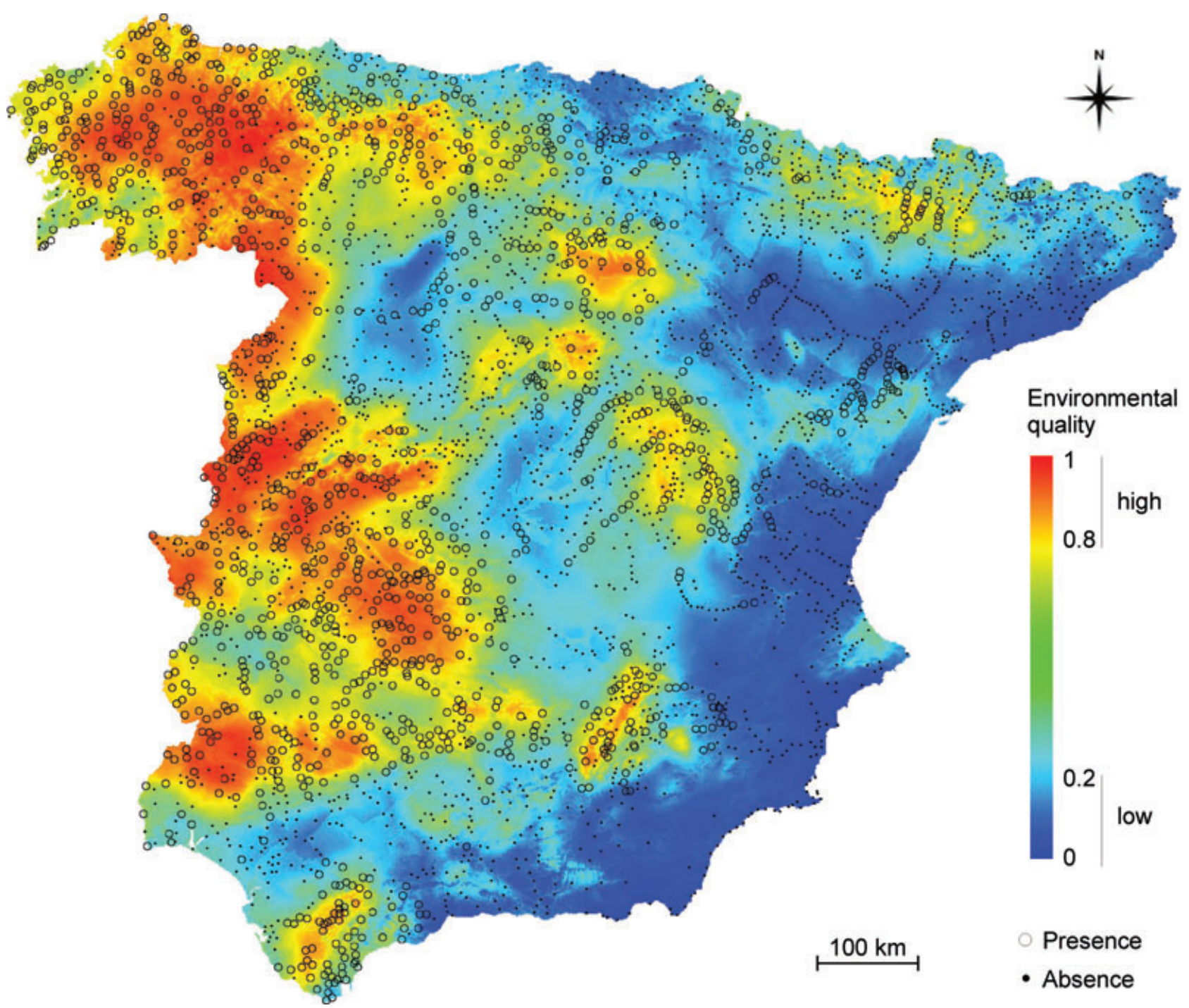

Figure 3. Fine-resolution presence and absence data for Eurasian otters in Spain (Ruiz-Olmo \& Delibes 1998) compared with environmental quality values at a resolution of $1 \times 1 \mathrm{~km}$ that were derived from the logistic regression model of Barbosa et al. (2003) at a $10 \times 10 \mathrm{~km}$ resolution.

models, respectively; and in $59.6 \%$ and $97.4 \%$ of $\mathrm{La} \mathrm{Ri-}$ oja random samples in the Spanish and Iberian models, respectively.

Downscaled environmental quality values generally matched the important conservation sites proposed by Queiroz et al. (1998) for the Iberian desman in Portugal (Fig. 2). Mean environmental quality values for these sites $\left(n=22991-\mathrm{km}^{2}\right.$ pixels) were 0.92 and 0.89 according to the Portuguese and Iberian models, respectively. These values were significantly higher (Wilcoxon tests, $p<0.001$ ) than those of the remaining 31,736 pixels within the area of Portugal we analyzed (Figs. 1 \& 2), where mean quality was already quite high $(0.71$ and 0.76 for the Portuguese and Iberian models, respectively) because the survey was conducted only within the species' distribution range in this country (Queiroz et al. 1998).

\section{Discussion}

For both Iberian desman and Eurasian otter, our downscaled predictions of environmental quality were significantly related to the location of survey sites selected by experts and presence as opposed to absence of the species at these sites. Predictions were also significantly related to the location of sites defined by experts as important for the conservation of desmans in Portugal. This suggests that such downscaled models may be a valid alternative to expert knowledge in the identification of optimal survey sites in regions that are relatively unknown and to field surveys where local distribution data cannot be collected. This possibility is especially relevant because fine-resolution information, however important to conservation efforts, is usually too costly and time 
consuming to collect across extensive areas. The cost of collecting such data is of particular concern in developing countries that contain high concentrations of species richness or endemism.

Kaliontzopoulou et al. (2008) found that for Podarcis lizards in North Africa fine-resolution data yielded more accurate models of maximum entropy than models derived from coarse-resolution data, even when the fine-resolution data set contained fewer records. Nevertheless, they related the difference in model success to the ecological traits of these species (small home range, aggregate distribution, low dispersal), so their conclusion may not necessarily hold for wider-ranging taxa. More importantly, coarser-resolution models are often the only option, and our results concur with Kaliontzopoulou et al.'s (2008) that good results can also be achieved when coarse-resolution models are applied at finer resolutions.

Downscaled $(1 \times 1 \mathrm{~km})$ models revealed local gradients of environmental quality for the modeled species within the $10 \times 10 \mathrm{~km}$ grid cells from which the modeled data were taken (Fig. 2). These gradients were not detectable in the original coarse-resolution models. In addition, the predictive ability of coarse-resolution and downscaled models generally was consistent, although the predictions of fine-resolution models were more accurate in some regions (e.g., La Rioja) than in others (e.g., Catalonia). This indicates that, although regional differences in the response of species to the environment may affect model performance at the local scale, a coarse-resolution model can still capture general gradients in environmental quality and perform satisfactorily at predicting species occurrence in particular places and at finer resolutions. The downscaled models may not have performed so well in Catalonia because there may have been variables acting at a fine scale in this region that were not included in the analysis or whose effects were not detectable at the coarser resolution.

The inclusion of a larger set of distribution data in the Iberian than in the national model of desmans allowed the detection of more details in this species' distribution, which was evident after extrapolation of the models to a finer resolution (Figs. $1 \& 2$ ). This was likely due to the inclusion of more predictor variables in the larger study area (Barbosa et al. 2009; Table 1). We found that models with a greater number of variables tended to produce predictions that were more detailed spatially (i.e., that showed greater heterogeneity on a finer scale). For desmans in Portugal and Spain, the Iberian model predicted survey locations more effectively than the national model. Models with relatively many variables, however, were not better than models with relatively few variables at predicting local presences and absences in the cases we analyzed.

Downscaled models predicted higher environmental quality values along rivers (Figs. $2 \& 3$ ), although the dis- tribution data that were modeled did not have enough resolution to reveal a close connection of the species to rivers and river locations were not explicitly included among the predictor variables (Barbosa et al. 2003, 2009; Table 1). Thus, the models were able to detect, even at a coarse resolution, an important ecological requirement of the modeled species, both of which are associated with freshwater environments. The models also distinguished between regions where species were widespread-apparently not being limited to the courses of the main rivers-and regions where the distribution of the species along particular rivers was easily differentiated from adjacent areas (Fig. 2). In these regions, the models indicated which watercourses (or portions thereof) were most likely to be associated with presence of the species and where the eventual building of infrastructures (e.g., dams or industrial settlements) could potentially fragment local populations.

The comparison of important conservation areas for desmans (Queiroz et al. 1998) with the predictions of our downscaled models of desman distribution (Fig. 2) also indicated that model predictions can identify roughly such areas. This was especially evident for northeastern Portugal (Fig. 2), where predicted environmental quality values along the important river stretches were clearly higher than the values predicted for adjacent areas. In areas where there were many river stretches identified as important for desmans, high predicted environmental quality values were widespread. We expect that local populations of the modeled species will be less fragmented in these areas because distances between favorable river stretches are shorter.

Vaughan and Ormerod (2003) argue that modeling success depends on sampling the entire environmental region within which an organism is present. Omitting part of this range from the models may result in incomplete species response curves that are different from the complete response curves, which limits the applicability of the model to areas outside the scope of the original model. Segurado and Araújo (2004) note that distribution ranges that lack clear geographical limits within a study area may prevent a model from detecting important environmental constraints on a species and thus limit the model's predictive power. Nevertheless, data are available often for only limited geographic regions or at coarser resolutions than is necessary to implement conservation measures; therefore, models seldom include the whole range of environmental conditions under which a species may occur. Although caution must be taken when extrapolating predictions, our results indicate that models of environmental favorability can have good predictive ability beyond their original scope, even when the analyzed territory does not include all possible environmental heterogeneity within the distribution area. The model of Portuguese desmans, which Barbosa et al. (2009) found was missing some relevant environmental 
constraints for this species in Iberia, still predicted effectively presence of desmans at a substantially finer resolution than that of the modeled data (Fig. 2), although at a finer resolution the variables can take values outside the range analyzed by the model, which were averaged over $10 \times 10 \mathrm{~km}$ squares. In addition, the otter model, despite including only a fraction of the species' global range (Ruiz-Olmo et al. 2008), captured the main descriptors of the distribution of otters within the study area and performed well at the original $10 \times 10 \mathrm{~km}$ resolution (Barbosa et al. 2003) and at a resolution that was 100 times finer (Fig. 3).

Downscaling of distribution models is possible whenever the predictor variables included in the model are available or can be interpolated at the necessary level of detail. The success of predictive models outside their original scope depends on factors that cannot all be taken into account (e.g., Randin et al. 2006). Both the species we analyzed are associated with aquatic systems. Nevertheless, the desman has specific environmental requirements. It occupies cold mountain waters within clearly delineated portions of the study area (Palomo \& Gisbert 2002; Fig. 1), whereas the otter inhabits all kinds of water bodies, from highland to coastal, fresh to brackish, and permanent to temporary, and has a broader spatial distribution (Ruiz-Olmo \& Delibes 1998; Fig. 3). This did not prevent the model of otters from detecting relevant environmental constraints for this species or from successfully predicting distributions even after extrapolation to a considerably finer resolution (Table 1).

This outcome may not occur for species that have no clear environmental associations or distribution limits within a study area (Segurado \& Araújo 2004). Investigations into the possibilities of model extrapolation should, therefore, also include species with such extensive distributions if fine-resolution data for model validation can be obtained. Nevertheless, downscaled models are usually needed for species with distributions that are subject to some constraint that can generally be detected through modeling. If further evidence of the reliability of our downscaling method, like any modeling approach, is needed for its application to other species and regions, we recommend conducting fine-resolution field surveys (whenever possible) on parts of the study area and comparing observations with the predictions of the downscaled model.

The large-scale models of environmental quality for the species we examined captured the main characteristics of the species' distributions even when the study area did not include most of the species' range. These models were still effective when used at a resolution 100 times finer than that of the modeled data and therefore could replace expensive and time-consuming field studies when they are not feasible. Coarse-resolution distribution data can thus be used, for this and other similar species, to build models that can be downscaled to identify areas along a gradient of environmental quality for the species at a local scale. Such models can be useful for choosing the best sites to survey for species occurrence within larger areas (e.g., $10 \times 10 \mathrm{~km}$ squares) to improve country-wide distribution maps; selecting optimal sites for collecting biological samples for genetic analysis in regions where the species' fine-resolution distribution is not well known; and identifying areas that are important for the species on a scale that is practical for the application of concrete conservation measures.

\section{Acknowledgments}

M. Grade, C. Soares, P. Acevedo, M. C. Fernández, and L. J. Palomo sent us useful information and data. A. Ozgul provided crucial tips on the use of $R$. This work was financed partly by the Spanish Ministerio de Educación y Ciencia (project CGL2009-11316, BOS subprogram). A.M.B. was supported by two fellowships (SFRH/BD/4601/2001 and SFRH/BPD/40387/2007) from Fundação para a Ciência e a Tecnologia, Portugal.

\section{Literature Cited}

Aguirre-Mendi, P. T. 2004. Distribución y estado de conservación del desmán ibérico, Galemys pyrenaicus (E. Geoffroy Saint-Hilaire, 1811) (Mammalia: Erinaceomorpha) en la Comunidad Autónoma de La Rioja. Zubía 22:55-85.

Araújo, M. B., W. Thuiller, P. H. Williams, and I. Reginster. 2005. Downscaling European species atlas distributions to a finer resolution: implications for conservation planning. Global Ecology and Biogeography 14:17-30.

Aymerich, P., F. Casadesús, and J. Gosálbez. 2001. Distribució de Galemys pyrenaicus (Insectivora, Talpidae) a Catalunya. Orsis 16:93-110

Barbosa, A. M., R. Real, J. Olivero, and J. M. Vargas. 2003. Otter (Lutra lutra) distribution modeling at two resolution scales suited to conservation planning in the Iberian Peninsula. Biological Conservation 114:377-387.

Barbosa, A. M., R. Real, and J. M. Vargas. 2009. Transferability of environmental favourability models in geographic space: the case of the Iberian desman (Galemys pyrenaicus) in Portugal and Spain. Ecological Modelling 220:747-754.

Fielding, A. H., and J. F. Bell. 1997. A review of methods for the assessment of prediction errors in conservation presence/absence models. Environmental Conservation 24:38-49.

Font, I. 1983. Atlas climático de España. Instituto Nacional de Meteorología, Madrid.

GRASS Development Team. 2009. Geographic resources analysis support system (GRASS) software. Open Source Geospatial Foundation, Vancouver, British Columbia. Available from http://grass.osgeo.org (accessed January 2009).

Guisan, A., and N. E. Zimmermann. 2000. Predictive habitat distribution models in ecology. Ecological Modelling 135:147-186.

Gutiérrez Illán, J., D. Gutiérrez, and R. J. Wilson. 2010. The contributions of topoclimate and land cover to species distributions and abundance: fine-resolution tests for a mountain butterfly fauna. Global Ecology and Biogeography 19:159-173.

Hosmer, D. W., and S. Lemeshow. 2000. Applied logistic regression. 2nd edition. John Wiley and Sons, New York. 
IGME (Instituto Geológico y Minero de España). 1979. Mapa hidrogeológico nacional. Explicación de los mapas de lluvia útil, de reconocimiento hidrogeológico y de síntesis de los sistemas acuíferos. 2nd edition. GME, Madrid.

IGN (Instituto Geográfico Nacional). 1999. Mapa de carreteras. Península Ibérica, Baleares y Canarias. Instituto Geográfico Nacional and Ministerio de Fomento, Madrid.

Kaliontzopoulou, A., J. C. Brito, M. A. Carretero, S. Larbes, and D. J. Harris. 2008. Modelling the partially unknown distribution of wall lizards (Podarcis) in North Africa: ecological affinities, potential areas of occurrence, and methodological constraints. Canadian Journal of Zoology 86:992-1001.

López-Darias, M., J. M. Lobo, and P. Gouat. 2008. Predicting potential distributions of invasive species: the exotic Barbary ground squirrel in the Canarian archipelago and the west Mediterranean region. Biological Invasions 10:1027-1040.

Mittermeier, R. A., P. Robles Gil, M. Hoffmann, J. Pilgrim, T. Brooks, C. Goettsch Mittermeier, J. Lamoreux, and G. A. B. da Fonseca. 2004. Hotspots revisited: earth's biologically richest and most endangered terrestrial ecoregions. Cemex, Monterrey, and University of Chicago Press, Chicago.

Muñoz, A. R., R. Real, A. M. Barbosa, and J. M. Vargas. 2005. Modelling the distribution of Bonelli's eagle in Spain: implications for conservation planning. Diversity and Distributions 11:477486.

Palomo, L. J., and J. Gisbert, editors. 2002. Atlas de los mamíferos terrestres de España. Dirección General de Conservación de la Naturaleza-SECEM-SECEMU, Madrid.

Quantum GIS Development Team. 2009. Quantum GIS. Geospatial Foundation, Vancouver, British Columbia. Available from http://qgis.osgeo.org (accessed January 2009).

Queiroz, A. I., C. M. Quaresma, C. P. Santos, A. J. Barbosa, and H. M. Carvalho. 1998. Bases para a conservação da toupeira-de-água, Galemys pyrenaicus. Estudos de Biologia e Conservação da Natureza, no. 27. ICN, Lisbon.

Randin, C. F., T. Dirnböck, S. Dullinger, N. E. Zimmermann, M. Zappa, and A. Guisan. 2006. Are niche-based species distribution models transferable in space? Journal of Biogeography 33:1689-1703.
R Development Core Team. 2009. R: a language and environment for statistical computing. R Foundation for Statistical Computing, Vienna. Available from http://www.r-project.org (accessed January 2009).

Real, R., A. M. Barbosa, and J. M. Vargas. 2006. Obtaining environmental favourability functions from logistic regression. Environmental and Ecological Statistics 13:237-245.

Real, R., A. M. Barbosa, A. Rodríguez, F. J. García, J. M. Vargas, L. J. Palomo, and M. Delibes. 2009. Conservation biogeography of ecologically-interacting species: the case of the Iberian lynx and the European rabbit. Diversity and Distributions 15:390-400.

Rojas, A. B., I. Cotilla, R. Real, and L. J. Palomo. 2001. Determinación de las áreas probables de distribución de los mamíferos terrestres en la provincia de Málaga a partir de las presencias conocidas. Galemys 13:217-229.

Ruiz-Olmo, J., and M. Delibes, editors. 1998. La nutria en España ante el horizonte del año 2000. Sociedad Española para la Conservación y Estudio de los Mamíferos, Málaga, Spain.

Ruiz-Olmo, J., A. Loy, C. Cianfrani, P. Yoxon, G. Yoxon, P. K. de Silva, A. Roos, M. Bisther, P. Hajkova, and B. Zemanova. 2008. Lutra lutra. In International Union for Conservation of Nature red list of threatened species. Version 2009.1. Available from www.iucnredlist.org (accessed September 2009).

Segurado, P., and M. B. Araújo. 2004. An evaluation of methods for modelling species distributions. Journal of Biogeography 31:1555-1568.

Sing, T., O. Sander, N. Beerenwinkel, and T. Lengauer. 2005. ROCR: visualizing classifier performance in R. Bioinformatics 21:3940-3941.

U. S. Geological Survey (USGS). 1996. GTOPO30. USGS, Land Processes Distributed Archive Center, Denver. Available from http://www.etsimo.uniovi.es/ feli/Data/Datos.html (accessed October 1999).

Vargas, J. M., M. A. Farfán, J. C. Guerrero, A. M. Barbosa, and R. Real. 2007. Geographical and environmental correlates of big and small game in Andalusia (southern Spain). Wildlife Research 34:498-506.

Vaughan, I. P., and S. J. Ormerod. 2003. Improving the quality of distribution models for conservation by addressing shortcomings in the field collection of training data. Conservation Biology 17:1601-1611.

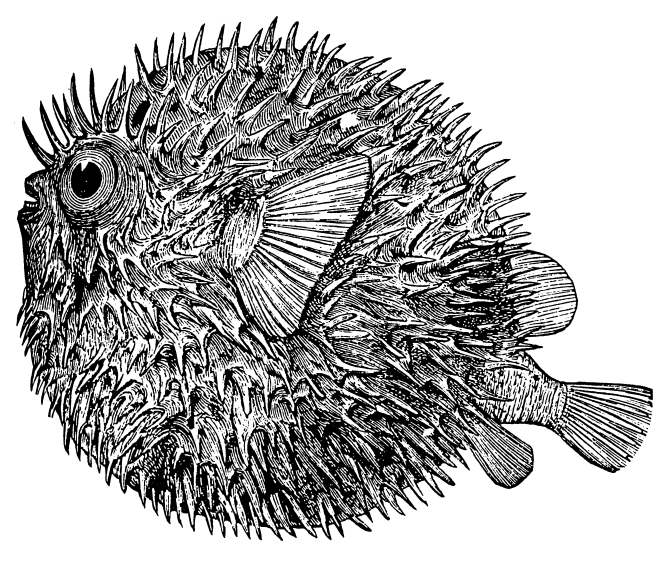

